\title{
The effect of local sources on particle size and chemical composition and their role in aerosol-cloud interactions at Puijo measurement station
}

\author{
H. Portin ${ }^{1}$, A. Leskinen ${ }^{1}$, L. Hao ${ }^{2}$, A. Kortelainen ${ }^{2}$, P. Miettinen ${ }^{2}$, A. Jaatinen ${ }^{2}$, A. Laaksonen ${ }^{2,3}$, K. E. J. Lehtinen ${ }^{1,2}$, \\ S. Romakkaniemi ${ }^{1}$, and M. Komppula ${ }^{1}$ \\ ${ }^{1}$ Finnish Meteorological Institute, P.O. Box 1627, 70211 Kuopio, Finland \\ ${ }^{2}$ University of Eastern Finland, Department of Applied Physics, P.O. Box 1627, 70211 Kuopio, Finland \\ ${ }^{3}$ Finnish Meteorological Institute, P.O. Box 503, 00101 Helsinki, Finland
}

Correspondence to: H. Portin (harri.portin@fmi.fi)

Received: 15 November 2013 - Published in Atmos. Chem. Phys. Discuss.: 9 December 2013

Revised: 9 May 2014 - Accepted: 13 May 2014 - Published: 18 June 2014

\begin{abstract}
Interactions between aerosols and liquid water clouds were studied during autumns 2010-2011 at a semiurban measurement station on Puijo tower in Kuopio, Finland. Cloud interstitial and total aerosol size distributions, particle chemical composition and hygroscopicity and cloud droplet size distribution were measured, with a focus on comparing clean air masses with those affected by local sources. On average, the polluted air contained more particles than the clean air masses, and generally the concentrations decreased during cloud events. Cloud processing was found to take place, especially in the clean air masses, and to a lesser extent in the polluted air. Some, mostly minor, differences in the average particle chemical composition between the air masses were observed. The average size and number concentration of activating particles were quite similar for both air masses, producing average droplet populations with only minor distinctions. As a case study, a long cloud event was analyzed in detail, with a special focus on the emissions from local sources, including a paper mill and a heating plant. This revealed larger variations in particle and cloud properties than the analysis of the whole data set. Clear differences in the total (between 214 and $2200 \mathrm{~cm}^{-3}$ ) and accumulation mode particle concentrations (between 62 and $169 \mathrm{~cm}^{-3}$ ) were observed. Particle chemical composition, especially the concentrations of organics (between 0.42 and $1.28 \mu \mathrm{g} \mathrm{m}^{-3}$ ) and sulfate (between 0.16 and $4.43 \mu \mathrm{g} \mathrm{m}^{-3}$ ), varied considerably. This affected the hygroscopic growth factor: for example, for $100 \mathrm{~nm}$ particles the range was from 1.21 to 1.45 at $90 \%$ relative humidity. Particularly, large particles, high hygroscop-
\end{abstract}

icities and elevated amounts of inorganics were linked with the pollutant plumes. Moreover, the particle hygroscopicity distributions in the polluted air were clearly bimodal, indicating externally mixed aerosol. The variable conditions also had an impact on cloud droplet formation, with the droplet concentration varying between 138 and $240 \mathrm{~cm}^{-3}$ and mean diameter between 9.2 and $12.4 \mu \mathrm{m}$.

\section{Introduction}

Anthropogenic aerosol particles such as sulfates and carbonaceous aerosols have significantly increased the global mean burden of atmospheric aerosol compared to preindustrial times. Prediction of the current and future behavior of the Earth's climate system is complicated by the large uncertainties associated with the indirect effects of atmospheric aerosols (Lohmann and Feichter, 2005; IPCC, 2013).

The indirect effect is characterized by the ability of aerosol particles to act as cloud condensation nuclei $(\mathrm{CCN})$ or ice nuclei. More $\mathrm{CCN}$ means more and smaller droplets, which leads to the Twomey effect: higher cloud albedo and increased reflection of solar radiation (Twomey, 1977). Another consequence is the Albrecht effect: since droplets are smaller, the cloud liquid water path increases, precipitation development is weaker and the clouds are more persistent (Albrecht, 1989). However, this effect is more complicated than the Twomey effect, because, if cloud thermodynamics 
and dynamics are considered, the liquid water path may also decrease (Han et al., 2002).

Particle size, number concentration and chemical composition are the key aerosol properties in the cloud droplet activation process (Dusek et al., 2006; Hudson, 2007), which has been confirmed in studies based on satellite observations (Brenguier et al., 2003; Sekiguchi et al., 2003), model calculations (Menon et al., 2002; Rotstayn and Liu, 2005) and in situ measurements (Coakley and Walsh, 2002; Wang et al., 2008). The effect of size and number concentration is well known (e.g., Vong and Covert, 1998; Henning et al., 2002; Komppula et al., 2005; Anttila et al., 2009), whereas the role of chemical composition is still under further investigation (e.g., Drewnick et al., 2007; Hao et al., 2013; Wu et al., 2013).

Using the ratio of the inorganic mass concentration to the total mass concentration (inorganic fraction, IO) as a measure of particle composition, Dusek et al. (2006) showed that $\sim 80 \%$ of the particle activation is explained by the particle size distribution and only $20 \%$ by particle chemical composition. Kivekäs et al. (2009) found a positive correlation between activation efficiency and IO, but IO was also correlated with accumulation mode particle concentration, making the separation of the effect of chemistry and particle size complicated.

Aerosol hygroscopicity defines how the particles grow at an elevated relative humidity and in the presence of a cloud. The distribution of the hygroscopic growth factor $\left(\mathrm{GF}_{\mathrm{H}}\right)$, determined as the ratio of wet to dry aerosol particle diameter, can be used as an indicator of the presence of less and more hygroscopic particles and thus the aerosol mixing state. However, $\mathrm{GF}_{\mathrm{H}}$ depends also on particle size (e.g., Sjogren et al., 2008; Kammermann et al., 2010; Fors et al., 2011), which is due to the Kelvin effect: for smaller particles, the partial pressure of water vapor on the more curved particle surface is higher, thus inhibiting the condensation of water. Furthermore, smaller particles are often less hygroscopic than larger particles, which are aged and possibly cloud processed.

So far, long-term in situ observations on aerosol-cloud interactions are available only from a few measurement stations, e.g., the Global Atmospheric Watch stations at Pallas, Finland (e.g., Komppula et al., 2005), and Jungfraujoch, Switzerland (e.g., Henning et al., 2002), as well as the SMEAR (Station for Measuring Forest EcosystemAtmosphere Relations) IV station at Puijo, Finland (Leskinen et al., 2009; Portin et al., 2009; Hao et al., 2013; Ahmad et al., 2013). Puijo is located in a semiurban environment, which makes it easier to investigate the effects of local pollutant sources and therefore the effect of aerosols with different chemical composition on aerosol-cloud interactions. In this paper we present the results from two intensive measurement campaigns (Puijo Aerosol Cloud Experiment, PuCE, 20 September-22 October 2010 and 26 September-31 October 2011) and provide new, detailed information about the effect of aerosols with different origins and chemical composition on the particle activation process in liquid water clouds.

\section{Methods}

\subsection{Site description}

The Puijo station resides on the top floor of the Puijo observation tower $\left(62^{\circ} 54^{\prime} 32^{\prime \prime} \mathrm{N}, 27^{\circ} 39^{\prime} 31^{\prime \prime} \mathrm{E} ; 306 \mathrm{~m}\right.$ above sea level, $224 \mathrm{~m}$ above the surrounding lake level), which is located in the city of Kuopio (105000 inhabitants), in a semiurban environment. Kuopio is situated in eastern Finland, about $330 \mathrm{~km}$ to the northeast of Helsinki. A map of the location of Kuopio and the area surrounding the tower is shown in Fig. 1, including the most important local sources: a paper mill in the north, the city center in the southeast, a heating plant in the south and a highway in the east in north-south direction. Also, residential areas of different sizes surround the tower, with the biggest in the east and south and smaller in the southwest, west and northwest. All local sources are located within $10 \mathrm{~km}$ from the tower at approximately $200 \mathrm{~m}$ lower altitude than the measurement level (Table 1). A more detailed overview of the station and the surrounding area can be found in Leskinen et al. (2009).

\subsection{Cloud events}

A cloud event was considered to take place at Puijo when the visibility at the top of the tower dropped below $200 \mathrm{~m}$. Below this limit the cloud and particle activation properties have been observed to be stable, providing data with best possible quality (Portin et al., 2009). The clouds with a visibility above $200 \mathrm{~m}$ may already be non-uniform and the time resolution of the twin-inlet system is not enough to distinguish quickly varying particle properties. Furthermore, cloud events (or cloud event hours; see Sect. 2.4) were classified as rainy if the average rain intensity exceeds $0.2 \mathrm{~mm} \mathrm{~h}^{-1}$. This classification was necessary, since rain drops remove both unactivated aerosol particles and cloud droplets, thus affecting the data.

\subsection{Instrumentation}

\subsubsection{Weather parameters}

The basic weather parameters were measured continuously at Puijo. Visibility and precipitation were observed with a present weather sensor (Vaisala FD12P). Wind speed and direction were measured with an ultrasonic two-dimensional anemometer (Thies UA2D). For temperature and relative humidity a Vaisala HMT337 temperature and relative humidity transmitter was used. All weather instruments were located approximately $2 \mathrm{~m}$ above the roof of the tower except for the anemometer, which was in a mast at a height of $5 \mathrm{~m}$ above the roof to decrease the effect of the tower on measured winds. 
Table 1. Sectors used for data classification and a list of local sources.

\begin{tabular}{llll}
\hline & Sector & Source & Direction and distance from the tower \\
\hline 1 & $0-45^{\circ}$ & Paper mill & $35^{\circ}, 5 \mathrm{~km}$ \\
& & Highway & $6-45^{\circ},>1.4 \mathrm{~km}$ \\
\hline 2 & $45-155^{\circ}$ & City center & $120-155^{\circ}, 1.6-3.2 \mathrm{~km}$ \\
& & Residential areas & $45-120^{\circ}, 1.2-4 \mathrm{~km}$ \\
& & Highway & $45-155^{\circ}, 1-1.4 \mathrm{~km}$ \\
\hline 3 & $155-215^{\circ}$ & Heating plant & $160^{\circ}, 3.5 \mathrm{~km}$ \\
& & Residential areas & $155-215^{\circ}, 3.4-10 \mathrm{~km}$ \\
& & Highway & $155-192^{\circ},>1 \mathrm{~km}$ \\
\hline 4 & $215-245^{\circ}$ & Residential areas & $215-245^{\circ}, 3.4-4 \mathrm{~km}$ \\
\hline 5 & $245-360^{\circ}$ & Residential areas & $245-360^{\circ}, 1.5-3.5 \mathrm{~km}$ \\
\hline
\end{tabular}
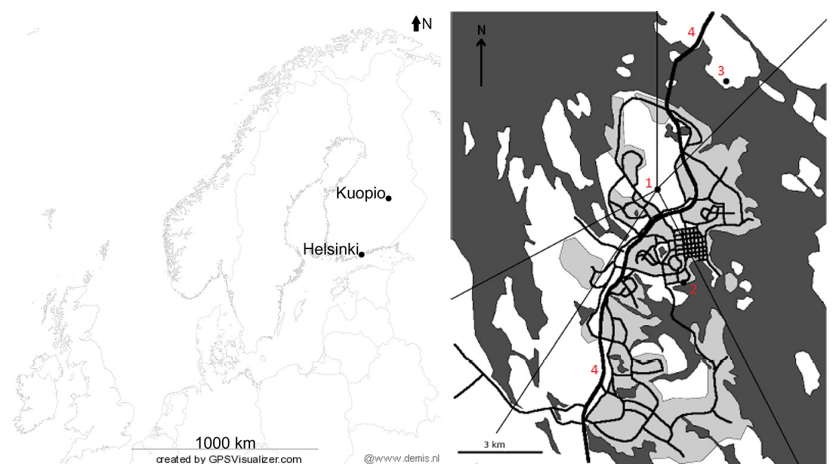

Figure 1. The location of Kuopio (left) and the map of the Kuopio area (right). Marked in the Kuopio area map are Puijo (1), a heating plant (2), a paper mill (3) and a highway (4). Dark-grey color indicates lakes; light-grey indicates residential areas and white forests. Also shown are the five sectors used in the data analysis to distinguish the effect of local sources (described in Sect. 2.4).

\subsubsection{Twin inlet system}

At the Puijo station the aerosol sample was collected with two separate inlets located on the top of the tower approximately $2.5 \mathrm{~m}$ above the roof. The sample was drawn through the roof of the tower to the measurement devices, which were located in a room on the top floor.

The interstitial inlet had a $\mathrm{PM}_{1}$ impactor (Digitel DPM10 with a $\mathrm{PM}_{1}$ nozzle plate for $1 \mathrm{~m}^{3} \mathrm{~h}^{-1}$ flow rate) to prevent the cloud droplets from entering the sample line. When a cloud was present, this inlet sampled only the interstitial aerosol since the cloud droplets were too large to enter the sampling line. The residence time of the aerosol sample in the sampling lines was more than $10 \mathrm{~s}$. By the time the sample reached the measurement devices, most of the water had evaporated from the particles as the sample air was warmed to the room temperature (e.g., Hinds, 1999).

The total air inlet had a cutoff size of approximately $40 \mu \mathrm{m}$. The inlet and the upper part of the sampling line were heated to $40^{\circ} \mathrm{C}$. Thus, when the tower was in a cloud, the total air inlet sampled both the cloud droplets and the unactivated, interstitial aerosol particles. Due to the heating the water from the droplets evaporated, leaving only the residual particles. This way it was possible to observe the aerosol size distribution as it would have been outside of the cloud.

During clear weather, both sampling lines measured the same aerosol distribution if the aerosol was not changing within 12 min measurement cycle. Between the main sampling lines and the measurement equipment was a valve system consisting of four controllable valves (Comparato, model Diamant 2000) that were used to switch the measurement devices between the sampling lines in 6 min intervals.

\subsubsection{Particle size distribution and number concentration}

Particles in the size range of 7 to $800 \mathrm{~nm}$ were measured with a twin differential mobility particle sizer (twin-DMPS) (Winklmayr et al., 1991; Jokinen and Mäkelä, 1997). One DMPS measured from 7 to $49 \mathrm{~nm}$ with sheath and sample flows of 13.4 and $2 \mathrm{Lpm}$, and the other from 27 to $800 \mathrm{~nm}$ with sheath and sample flows of 5.5 and $1 \mathrm{Lpm}$, respectively. Flow checks were made periodically. For the size range of 20-200 nm, where majority of the cloud droplet formation takes place, the accuracy of the DMPS was estimated to be $10 \%$, as discussed in Wiedensohler et al. (2012). The instrument was connected to the twin inlet system at all times and a full size distribution for both sampling lines was provided with a 12 min time resolution. The times of the measured size distributions from interstitial and total lines differed by $6 \mathrm{~min}$, which had to be considered in the data analysis, normally by averaging over a particular time period. By comparing the size distributions between the sampling lines, it was possible to observe the size dependent cloud droplet activation of the particles.

In this study, we defined the nucleation mode particle concentration $\left(N_{\text {nuc }}\right)$ as the concentration of particles 
with a diameter $D_{\mathrm{p}}<25 \mathrm{~nm}$. For Aitken mode particle concentration $\left(N_{\mathrm{ait}}\right)$ the corresponding size range is $25 \mathrm{~nm}<D_{\mathrm{p}}<100 \mathrm{~nm}$ and for the accumulation mode concentration $\left(N_{\text {acc }}\right) D_{\mathrm{p}}>100 \mathrm{~nm}$. Moreover, $D_{50}$ was defined as the diameter above which at least $50 \%$ of the particles have activated into cloud droplets (Komppula et al., 2005).

\subsubsection{Cloud droplets}

Cloud droplets were observed with a cloud droplet probe (CDP, Droplet Measurement Technologies) with a $10 \mathrm{~s}$ time resolution. The CDP measured the cloud droplet size distribution in the size range of 3 to $50 \mu \mathrm{m}$ by classifying the droplets into 30 size bins according to the scattered light of a laser beam at a wavelength of $658 \mathrm{~nm}$. The cloud droplet number concentration in each size bin was calculated by dividing the raw droplet counts with the volume of air passing through the sampling area of the laser beam. The instrument had a custom-built tubular inlet with an external pump to provide a constant sample flow $\left(13 \mathrm{~m} \mathrm{~s}^{-1}\right.$, checked in the beginning of both campaigns). It was mounted on a swivel, which kept the inlet facing the wind. The accuracy of the CDP was estimated to be 20-30\%, typical for other devices with the same detection principle (e.g., forward-scattering spectrometer probe, FSSP) (Brenguier and Bourrianne, 1998). The size detection of the probe was proven with glass beads of 5 to $40 \mu \mathrm{m}$ in diameter in the beginning of both campaigns. The CDP data were also used to estimate the cloud liquid water content (LWC) by calculating the total volume of the droplet population.

\subsubsection{Particle chemical composition}

The particle chemical composition was studied with an Aerodyne high-resolution aerosol time-of-flight mass spectrometer (HR-ToF-AMS; DeCarlo et al., 2006). An aerodynamic lens focuses the particles into a narrow beam, which enters a vacuum, where the particles are flash-vaporized and ionized. The ion fragments are detected by a time-of-flight mass spectrometer.

The aerosol mass spectrometer (AMS) provides the mass concentrations of organics, sulfate, nitrate, ammonium and chloride in the size range $40 \mathrm{~nm}<D_{\mathrm{p}}<1 \mu \mathrm{m}$. However, in this study the chloride data were omitted since the concentrations at Puijo were negligible. The inorganic fraction (IO) was defined as the ratio of the inorganic mass concentration to the total mass concentration. Twin inlet data for the AMS were available for the whole 2011 campaign. In the 2010 campaign, the AMS was connected to the twin inlet system for a period of only $28 \mathrm{~h}$ for a case study (Hao et al., 2013), otherwise to the total line. To obtain uniform data from both campaigns, AMS data collected from the total line were used when discussing the whole 2010-2011 data set and twin-inlet data in the case study from the 2011 campaign.

\subsubsection{Particle hygroscopicity}

A hygroscopicity tandem differential mobility analyzer (HTDMA; Joutsensaari et al., 2001) was used to observe the hygroscopic growth of aerosol particles during PuCE 2011. In order to measure dry aerosol, the device was connected directly to the total line instead of switching between the two sampling lines. The setup has a humidifier between the two DMAs. The first DMA selects particles with a certain dry size from the original polydisperse aerosol. In this study, the selected dry sizes were 80,100 and $150 \mathrm{~nm}$. The monodisperse aerosol enters the humidifier, which is set at $90 \%$ relative humidity. The size distribution of the humid aerosol is measured with the second DMA. From this size distribution the average hygroscopic growth factor $\left(\mathrm{GF}_{\mathrm{H}}\right.$, the ratio of wet to dry particle diameter) for a certain dry diameter was calculated. The instrument measured one dry size for $5 \mathrm{~min}$, so a full cycle took about $15 \mathrm{~min}$. As the H-TDMA was operated only for a few days during the 2011 campaign, the data will be presented for the case study only.

Typical values of $\mathrm{GF}_{\mathrm{H}}$ for $100 \mathrm{~nm}$ ambient aerosol particles $\left(\mathrm{GF}_{100}\right)$ vary from 1.0 to 1.5 (Sjogren et al., 2008). Black carbon is hydrophobic $\left(\mathrm{GF}_{\mathrm{H}}=1.0\right)$, organics are less hygroscopic $\left(\mathrm{GF}_{\mathrm{H}} \approx 1.2\right)$ and anthropogenic particles with higher IO are more hygroscopic $\left(\mathrm{GF}_{\mathrm{H}}>1.3\right)$. The ratio between the number concentrations of more and less hygroscopic particles was defined as $R_{\mathrm{GF}}=N_{\mathrm{GF}>1.25} / N_{\mathrm{GF} \leq 1.25}$, where $N_{\mathrm{GF}>1.25}$ and $N_{\mathrm{GF} \leq 1.25}$ are the number concentrations of particles with $\mathrm{GF}_{\mathrm{H}}$ more than and less than or equal to 1.25 , respectively. The limit 1.25 was chosen as it represented in most cases the midpoint between the low $\mathrm{GF}_{\mathrm{H}}$ and high $\mathrm{GF}_{\mathrm{H}}$ modes of the hygroscopicity distributions of this study and the same limit was also used in Kammermann et al. (2010).

\subsection{Data evaluation}

As the first step of the data analysis, $1 \mathrm{~h}$ averages were calculated for the whole data set from both 2010 and 2011 campaigns, except for the CDP, for which the $10 \mathrm{~s}$ data were used. The averaging was done in order to even out discrepancies in the twin-DMPS size distributions between the sampling lines.

The hours with average visibility below $200 \mathrm{~m}$ were classified as cloud event hours. For the case study (Sect. 3.3), instead of hourly averages, the data were averaged over the different subperiods.

An hour was classified as a clear hour if the average relative humidity was below $80 \%$ or the average height of the lowest cloud layer, measured by a ceilometer (Vaisala CT25K) located in a nearby weather station, was over $500 \mathrm{~m}$ ( $\sim 300 \mathrm{~m}$ above the top of the tower). The choice of using these criteria instead of some high value for visibility was made because even at visibilities $>40 \mathrm{~km}$, relative humidities 
higher than $90 \%$ were sometimes observed, which was enough to have a noticeable effect on the twin inlet data.

To study the possible effects of the different local sources, the area surrounding the tower was divided into five sectors according to the local sources described in Sect. 2.1 (Table 1). The same sectors were also used in Leskinen et al. (2012). It must be noted that the local sources resided some $200 \mathrm{~m}$ lower, excluding the heating plant and paper mill, whose emission heights were about 80 and $128 \mathrm{~m}$ lower than the measurement altitude.

\section{Results and discussion}

\subsection{Overview of cloud events}

During PuCE 2010 and 2011, 39 cloud events were observed, ranging from short periods of $15 \mathrm{~min}$ to events lasting up to $31 \mathrm{~h}$. In total, these events provided 156 cloud event hours (visibility $<200 \mathrm{~m}$ ). The majority of the cloud event hours took place when the wind direction was from sector $3(69 \mathrm{~h})$ or sector $5(50 \mathrm{~h})$. It is very likely that the air masses coming from sector 5 are cleaner and of marine origin (Portin et al., 2009). However, these air masses have spent some time over the continent, which has removed most of the marine characteristics, as indicated by, for example, the absence of chloride. The air masses from sector 3, however, were affected by the local sources. Thus, from now on, the results and discussion presented here will focus on the comparison of these two sectors, which will be referred to as polluted (3) and clean (5) sectors, respectively.

\subsection{Aerosol-cloud interactions for air masses with and without local pollutant sources}

\subsubsection{Particle size distribution}

A summary of the aerosol properties for the sectors with and without local pollutant sources is shown in Table 2 along with the average values calculated from the whole data set. All the particle data discussed are from the total air inlet, if not mentioned otherwise. Also, the standard error of the mean was calculated for the observations for the times corresponding to the $1 \mathrm{~h}$ averages. The values were calculated for clear ( $\mathrm{RH}<80 \%$ or height of the lowest cloud $>500 \mathrm{~m})(943 \mathrm{~h}$ in total) and cloudy conditions $(156 \mathrm{~h})$ during the campaigns. The corresponding average size distributions are shown in Fig. 2. The average particle number concentration $\left(N_{\text {tot }}\right)$ in the air masses coming from the polluted sector in clear conditions $\left(2930 \mathrm{~cm}^{-3}\right)$ was higher than that of the clean sector $\left(2000 \mathrm{~cm}^{-3}\right)$ for all particle sizes. The mean total particle volume concentrations ( $\left.V_{\text {tot }}\right)$ were 3.0 and $0.80 \mu \mathrm{m}^{3} \mathrm{~cm}^{-3}$ for the polluted and clean sectors, respectively. Furthermore, the size distribution for the polluted sector was much broader, suggesting that the particles had originated from multiple sources.
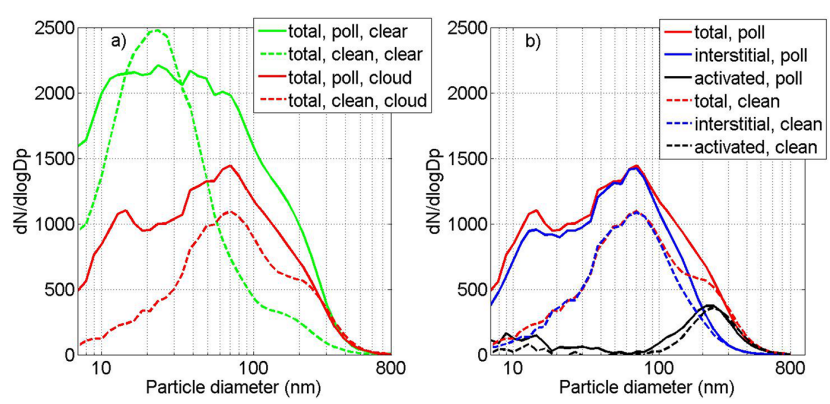

Figure 2. (a) Average total particle size distributions in both clear and cloudy conditions and (b) average total, interstitial and activated particle size distributions for polluted and clean sectors in cloudy conditions.

In cloudy conditions, the mean $N_{\text {tot }}$ decreased by $43 \%$ for the polluted and by $51 \%$ for the clean sector due to particles impacting into cloud droplets and wet removal. Scavenging was most significant for nucleation mode particles, leading to an increase in the geometric mean particle diameters (GMD) of the total aerosol (Fig. 2, Table 2). For the clean sector the GMD increased by $120 \%$, which is considerably more than the $16 \%$ increase for the polluted sector. The $V_{\text {tot }}$ was equal $\left(2.5 \mu \mathrm{m}^{3} \mathrm{~cm}^{-3}\right)$ for both sectors in cloudy conditions. For the clean sector the $V_{\text {tot }}$ in cloudy conditions was 3 times that in clear conditions. The differences in the particle populations of the two sectors can be explained by cloud processing: some of the smaller particles diffused to droplets and trace gases converted to particulate matter within the droplets. This increased the size of the activated particles and produced bimodal size distributions when the cloud droplets evaporated.

The cloud processing is often most evident in clean, marine aerosol (e.g., Hoppel et al., 1986; Frick and Hoppel, 1993; Mochida et al., 2011). At Puijo, cloud processing has been observed in the air masses from both sectors, but it was more distinguishable in the air masses arriving from the clean sector. For the polluted sector the effect of cloud processing was partly masked by the higher $N_{\text {tot }}$. A clear hump can be seen in the clean sector size distribution at around $200 \mathrm{~nm}$ (Fig. 2b), indicating cloud processing. The hump is also seen in the size distribution measured in clear conditions (Fig. 2a), meaning that the air masses have gone through cloud formation and processing on their way to Puijo. For the polluted sector, the hump can also be observed in both clear and cloudy conditions, but it overlaps more with the Aitken mode.

\subsubsection{Particle activation and cloud droplet size distribution}

The average activated fractions as a function of particle diameter for the two sectors were calculated from the particle size distribution data provided by the twin-DMPS (Fig. 3). For the polluted sector, even smaller particles activated and 
Table 2. Average values and standard deviations of total particle number concentration $\left(N_{\text {tot }}\right)$, geometric mean particle diameter (GMD), total particle volume concentration $\left(V_{\text {tot }}\right)$, number concentrations of nucleation, Aitken and accumulation mode particles ( $\left.N_{\text {nuc }}, N_{\text {ait }}, N_{\text {acc }}\right)$ and ratio $N_{\text {ait }} / N_{\text {acc}}$. Values are calculated from the twin-DMPS data for the sectors with and without local pollutant sources, for the whole data set and for both clear and cloudy conditions. Data are from the total sampling line.

\begin{tabular}{|c|c|c|c|c|c|c|c|c|c|c|c|c|c|c|}
\hline \multirow[t]{2}{*}{ Sector } & \multicolumn{2}{|c|}{$N_{\text {tot }}\left(\mathrm{cm}^{-3}\right)$} & \multicolumn{2}{|c|}{ GMD (nm) } & \multicolumn{2}{|c|}{$V_{\text {tot }}\left(\mu \mathrm{m}^{3} \mathrm{~cm}^{-3}\right)$} & \multicolumn{2}{|c|}{$N_{\text {nuc }}\left(\mathrm{cm}^{-3}\right)$} & \multicolumn{2}{|c|}{$N_{\text {ait }}\left(\mathrm{cm}^{-3}\right)$} & \multicolumn{2}{|c|}{$N_{\mathrm{acc}}\left(\mathrm{cm}^{-3}\right)$} & \multicolumn{2}{|c|}{$N_{\text {ait }} / N_{\text {acc }}$} \\
\hline & clear & cloud & clear & cloud & clear & cloud & clear & cloud & clear & cloud & clear & cloud & clear & cloud \\
\hline polluted & $2930 \pm 2030$ & $1680 \pm 1020$ & $44 \pm 19$ & $51 \pm 24$ & $3.0 \pm 2.2$ & $2.5 \pm 2.7$ & $1170 \pm 1780$ & $511 \pm 580$ & $1180+525$ & $727 \pm 436$ & $580 \pm 384$ & $438 \pm 490$ & $3.2 \pm 3.0$ & $2.8 \pm 2.3$ \\
\hline clean & $2000 \pm 1510$ & $972 \pm 771$ & $35 \pm 20$ & & $0.80 \pm 0.94$ & $2.5 \pm 2.3$ & $1040 \pm 1250$ & $126 \pm$ & $2+5$ & $498=$ & $146 \pm$ & & $9.2 \pm 8.8$ & $2.5 \pm 2.6$ \\
\hline all & $2480 \pm 2440$ & $1530 \pm 1100$ & $39 \pm 21$ & $59 \pm 29$ & $1.6 \pm 1.8$ & $2.6 \pm 2.4$ & $1070 \pm 2120$ & $443 \pm 624$ & $1000 \pm 652$ & $669 \pm 452$ & $311 \pm 312$ & $416 \pm 392$ & $6.6 \pm 7.0$ & $2.6 \pm 2.6$ \\
\hline
\end{tabular}

Table 3. Average values and standard deviations of number concentration of activated particles ( $N_{\text {act }}$, calculated as the concentration difference between the total and interstitial lines), cloud droplet number concentration $\left(N_{\mathrm{d}}\right)$, droplet diameter $\left(D_{\mathrm{d}}\right)$ and liquid water content (LWC) in cloudy conditions for the sectors with and without local pollutant sources and for the whole data set.

\begin{tabular}{lllll}
\hline Sector & $N_{\mathrm{act}}\left(\mathrm{cm}^{-3}\right)$ & $N_{\mathrm{d}}\left(\mathrm{cm}^{-3}\right)$ & $D_{\mathrm{d}}(\mu \mathrm{m})$ & $\mathrm{LWC}\left(\mathrm{g} \mathrm{m}^{-3}\right)$ \\
\hline polluted & $210 \pm 148$ & $293 \pm 159$ & $8.3 \pm 2.3$ & $0.14 \pm 0.13$ \\
clean & $165 \pm 126$ & $266 \pm 124$ & $8.9 \pm 2.2$ & $0.14 \pm 0.09$ \\
all & $209 \pm 186$ & $285 \pm 168$ & $8.9 \pm 2.3$ & $0.15 \pm 0.12$ \\
\hline
\end{tabular}

the activation curve is less steep than for the clean sector. The steepness of the activation curve gives information about the aerosol mixing state (Asmi et al., 2012). A steeper curve, like the one observed for the clean sector, is an indication of more internally mixed and more aged particles. A less steep curve means that aerosol from several sources with variable chemical composition and hygroscopic properties has been present, as was the case for the polluted sector. The number concentration of activated particles $\left(N_{\text {act }}\right.$, calculated as the concentration difference between the total and interstitial sampling lines) differed by $21 \%$ between the two sectors, being 210 and $165 \mathrm{~cm}^{-3}$ for polluted and clean, respectively (Table 3). However, the size distributions of the activated particles were very similar for both sectors (Fig. 2b). The only difference was that the size distribution for the polluted sector was tilted towards smaller particle sizes, which also explains the difference in $N_{\text {act }}$.

The average cloud droplet concentrations provided by the $\operatorname{CDP}\left(N_{\mathrm{d}}\right)$ were 293 and $266 \mathrm{~cm}^{-3}$ for the polluted and clean sectors, respectively. These numbers are comparable to $N_{\text {act }}$ within the instrumental uncertainties of 10 and $30 \%$ of the DMPS and CDP, respectively. The arithmetic mean droplet diameters $\left(D_{\mathrm{d}}\right)$ were 8.3 and $8.9 \mu \mathrm{m}$ for the polluted and clean sectors, respectively (Table 3 ). Although these differences were small, this is just what one would expect based on the particle population properties of the two sectors. Higher $N_{\text {tot }}$, especially $N_{\text {acc }}$, of the polluted sector favored more and smaller droplets. The LWCs were equal, $0.14 \mathrm{~g} \mathrm{~m}^{-3}$, for both sectors.
It must be emphasized that the differences in the properties of activated particles and cloud droplets between the two sectors were small. Also, there was a lot of variability in the data, as indicated by the high standard deviations (Table 3 ). This means that the these data have to be interpreted with caution and that more detailed studies, like the case study presented in Sect. 3.3, are needed to support the conclusions presented here.

\subsubsection{Particle chemical composition}

The mass concentrations of the chemical components for the two sectors are shown in Table 4. In clear conditions, as one would expect based on the larger number of particles, the average concentrations of all measured constituents (organics, sulfate, nitrate, ammonium) were higher in the polluted than in the clean air masses. In cloudy conditions, compared to the clear conditions, the nitrate concentration was the same but the organics, sulfate and ammonium concentrations were lower by 18,9 , and $33 \%$, respectively, for the polluted sector. For the clean sector, as a considerable increase in $N_{\text {acc }}$ took place (Fig. 2), the concentration of all constituents were higher by a factor of 2 to 6 compared to the clear conditions. For nitrate the concentration even exceeded that of the polluted sector, and for ammonium the concentrations were equal. The IO was between 42 and $44 \%$ for both sectors and for both clear and cloudy conditions.

The most significant differences in the in-cloud aerosol composition between the two sectors were the higher concentration of sulfate for the polluted sector compared to the clean sector ( $\left.1.08 \mathrm{vs.} 0.69 \mathrm{\mu g} \mathrm{m}^{-3}\right)$ and the lower concentration of nitrate $\left(0.19\right.$ vs. $\left.0.24 \mu \mathrm{g} \mathrm{m}^{-3}\right)$. The elevated sulfate may be linked to the local pollutant sources, which produce either sulfate particles directly or then $\mathrm{SO}_{2}$ that is converted into particulate sulfate. The more acidic aerosol could also explain the lower nitrate concentration of the polluted sector.

However, based on this analysis, it is impossible to distinguish between the effects of local sources and possible air mass transport from elsewhere on the polluted sector aerosol. Furthermore, as was the case with the particle activation and cloud droplet data discussed in the previous section, the standard deviations were also large for the particle chemical composition, indicating highly varying aerosol properties. 
Table 4. Average mass concentrations and standard deviations of the chemical constituents measured by the AMS for the sectors with and without local pollutant sources, for the whole data set and for both clear and cloudy conditions. Data are from the total sampling line.

\begin{tabular}{lll|ll|ll|l|l|l|l|l}
\hline \multirow{2}{*}{ Sector } & \multicolumn{2}{c|}{ Organics $\left(\mu \mathrm{g} \mathrm{m}^{-3}\right)$} & \multicolumn{2}{|c|}{ Sulfate $\left(\mu \mathrm{g} \mathrm{m}^{-3}\right)$} & \multicolumn{2}{|c|}{ Nitrate $\left(\mu \mathrm{g} \mathrm{m}^{-3}\right)$} & \multicolumn{2}{|c|}{ Ammonium $\left(\mu \mathrm{m} \mathrm{m}^{-3}\right)$} & Inorg/total $(\%)$ \\
\cline { 2 - 10 } & clear & cloud & clear & cloud & clear & cloud & clear & cloud & clear & cloud \\
\hline polluted & $2.17 \pm 2.1$ & $1.79 \pm 2.25$ & $1.19 \pm 1.1$ & $1.08 \pm 1.26$ & $0.21 \pm 0.27$ & $0.19 \pm 0.18$ & $0.40 \pm 0.42$ & $0.27 \pm 0.29$ & $42 \pm 12$ & $44 \pm 18$ \\
clean & $0.48 \pm 2$ & $1.61 \pm 1.1$ & $0.27 \pm 0.34$ & $0.69 \pm 0.55$ & $0.04 \pm 0.02$ & $0.24 \pm 0.15$ & $0.05 \pm 0.07$ & $0.27 \pm 0.22$ & $42 \pm 29$ & $43 \pm 17$ \\
all & $1.22 \pm 3.2$ & $1.62 \pm 1.9$ & $0.71 \pm 0.93$ & $0.92 \pm 1.06$ & $0.13 \pm 0.22$ & $0.21 \pm 0.17$ & $0.22 \pm 0.35$ & $0.28 \pm 0.26$ & $43 \pm 22$ & $46 \pm 18$ \\
\hline
\end{tabular}

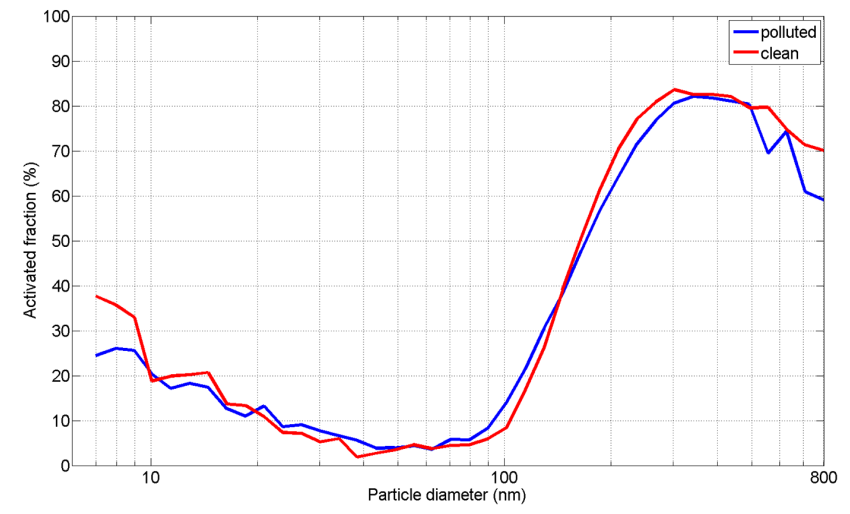

Figure 3. Average activated fractions as a function of particle diameter for polluted and clean sectors.

\subsection{A case study on the effect of local sources on aerosol-cloud interactions}

During PuCE 2011, a long cloud event took place between 22 October, 09:00 LT, and 24 October, 05:15 LT, lasting in total $44 \mathrm{~h}$. The wind direction, temperature and rain intensity varied considerably during the event. Also, different air masses and pollutant plumes from local sources were observed. Thus, it was possible to perform a detailed analysis on the effects of these variable conditions on aerosolcloud interactions. The event could be divided into eight "sub-events" (Table 5). The time series of the most important weather and other parameters are shown in Figs. 4 and 5.

\subsubsection{Rainy period}

The rainy period, with a southerly wind from the polluted sector, a temperature of slightly over $0^{\circ} \mathrm{C}$ and some rain (on average $0.8 \mathrm{~mm} \mathrm{~h}^{-1}$ ), was characterized by the highest $N_{\text {tot }}$ of all cloud periods (Table 6). This was mainly explained by a high $N_{\text {ait }}$ (Fig. 6a), probably from fresh, anthropogenic emissions. $N_{\text {acc }}$ was relatively high compared to the other periods, leading to a high droplet number concentration $N_{\mathrm{d}}$ with the smallest $D_{\mathrm{d}}$ of all the periods. Normally, the droplet size distribution was bimodal, with the first mode around $10 \mu \mathrm{m}$ and second mode at $\sim 16 \mu \mathrm{m}$ (Fig. 6d). For this period, however, only the first mode was observed with a high amount of small

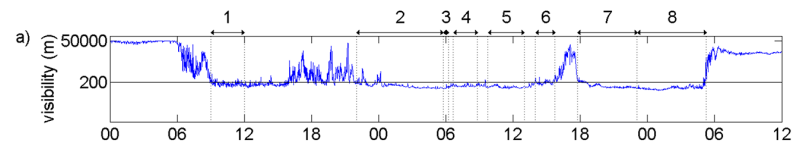

b)
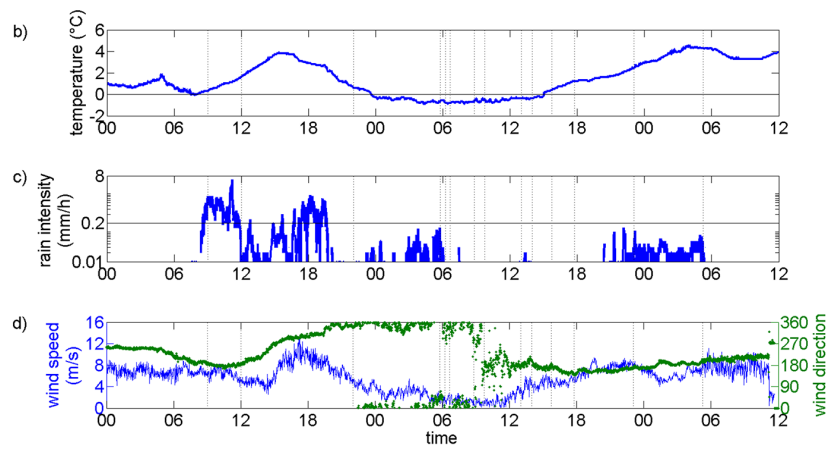

Figure 4. Time series of weather parameters observed during the cloud event on 22-24 October 2011. (a) Visibility, (b) temperature, (c) rain intensity, and (d) wind speed (left axis) and direction (right axis). Different periods described in the text are marked with dashed lines and also with numbered arrows above (a) (1, rainy; 2, clean; 3 , paper mill; 4 , clean $2 ; 5$, heating plant; 6 , southern $1 ; 7$, southern 2 ; and 8 , southern 3 ).

droplets. LWC during this period was the lowest during the whole event, so it is possible that the droplet growth was limited by the availability of water.

The activated fraction of particles for this period remained low, even for the larger particles, reaching only $80 \%$ (Fig. 6c). This may also have been caused by the removal of droplets by rain, which affects the particle measurements. Unfortunately, as can be seen from Fig. 6a and c, the low amount of particles in the upper limit of DMPS measurement range provides poor statistics, wrongly suggesting very low activated fractions for particles larger than $600 \mathrm{~nm}$ in diameter. Furthermore, the particle activation data in Fig. 6b and $\mathrm{c}$ suggest that also the smallest particles contributed to droplet formation. This inaccuracy was likely caused by the large variation in the concentrations of small particles; the 6 min time difference between the interstitial and total sampling lines; and for some of the periods, the short averaging time. This has to be kept in mind when interpreting Fig. $6 \mathrm{~b}$ and $\mathrm{c}$, and hence the data for particles smaller than $80 \mathrm{~nm}$ in diameter are illustrated with dashed lines. 
Table 5. Summary of the different periods during the cloud event observed in 22-24 October 2011.

\begin{tabular}{llllrl}
\hline & Period & Time & Sector & Temperature $\left({ }^{\circ} \mathrm{C}\right)$ & Special characteristics \\
\hline 1 & rainy & 22 October, 09:00-12:00 & polluted & 0.9 & rainy \\
2 & clean & 22-23 October, 22:00-05:45 & clean & -0.3 & none \\
3 & paper mill & 23 October, 05:45-06:15 & 1 & -0.6 & paper mill plume \\
4 & clean 2 & 23 October, 06:40-08:50 & clean, 1 & -0.7 & none \\
5 & heating plant & 23 October, 09:45-13:00 & polluted & -0.5 & heating plant plume \\
6 & southern 1 & 23 October, 14:00-15:45 & polluted & 0 & none \\
7 & southern 2 & 23 October, 17:45-23:05 & polluted & 1.6 & none \\
8 & southern 3 & 23-24 October, 23:05-05:15 & polluted & 3.6 & none \\
\hline
\end{tabular}
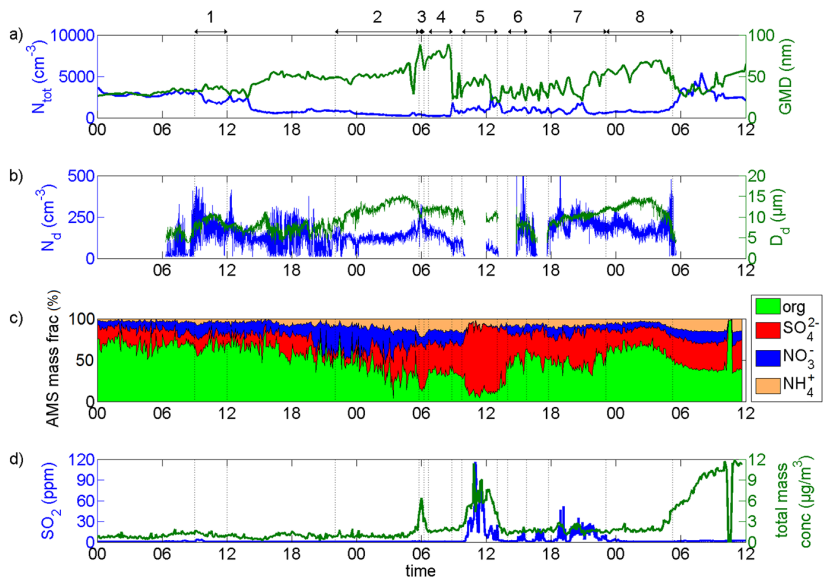

Figure 5. Time series during the cloud event on 22-24 October 2011 of (a) total particle number concentration (left axis) and geometric mean particle diameter (right axis), (b) cloud droplet number concentration (left axis) and mean droplet diameter (right axis), (c) mass fractions of different chemical components measured by the AMS and (d) $\mathrm{SO}_{2}$ concentration (left axis) and total particle mass concentration measured by the AMS (right axis). Different periods described in the text are marked with dashed lines and also with numbered arrows above (a) (1, rainy; 2 , clean; 3 , paper mill; 4, clean 2 ; 5 , heating plant; 6 , southern $1 ; 7$, southern 2 ; and 8 , southern 3 ).

The chemical composition of particles was dominated by organics, with the concentrations of other components remaining low (Table 7). The activated fraction of organics was the lowest for all periods. Also, the particles during this period had a low average hygroscopicity (Table 8 ), with very low $R_{\mathrm{GF}}$ indicating a strong contribution from the low $\mathrm{GF}_{\mathrm{H}}$ particles. The growth factor distribution was clearly bimodal, especially for the $80 \mathrm{~nm}$ particles (Fig. 6e, f). It is likely that the nonhygroscopic mode consisted of particles containing organics or black carbon, some of which remained unactivated. The largest residential areas and the majority of the traffic in Kuopio are concentrated to the south of the tower. Both biomass burning and traffic-related combustion aerosols are known to be less hygroscopic (Herich et al., 2009). This could also partly explain the low activated fraction.
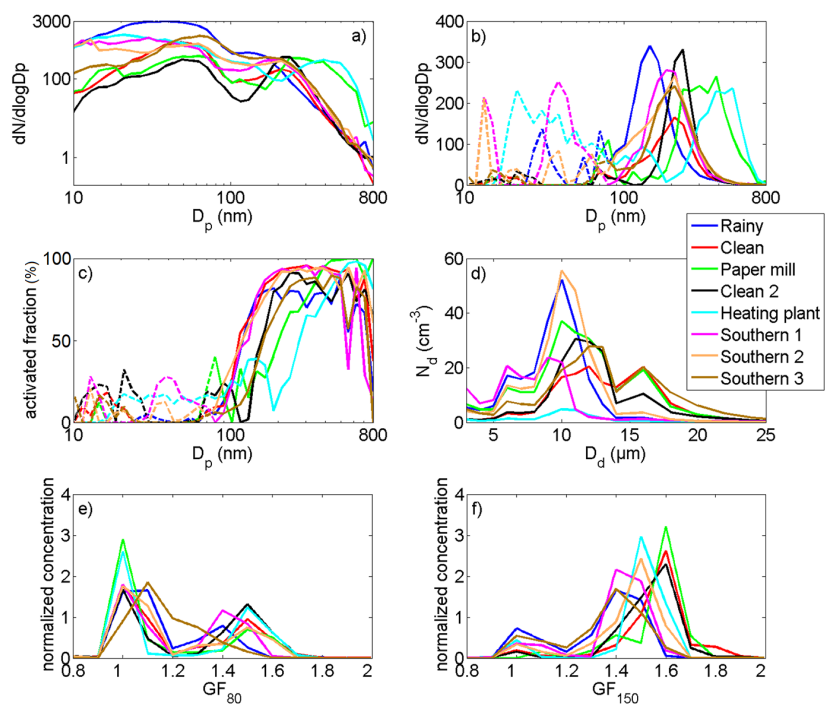

Figure 6. (a) Total particle size distributions, (b) size distributions of activated particles, (c) activated fraction of particles as a function of particle diameter, (d) cloud droplet size distributions and growth factor distributions for (e) $80 \mathrm{~nm}$ and (f) $150 \mathrm{~nm}$ particles for the different periods of the cloud event observed on 22-24 October 2011. In (b) and (c) data for particles smaller than $80 \mathrm{~nm}$ in diameter are illustrated with dashed lines due to the inaccuracies discussed in the text. In (e) and (f) normalized concentration means that the integral of the particle concentrations over $\mathrm{GF}=100$.

\subsubsection{Clean period}

During the clean period, air masses were coming from the clean sector, there was no rain and the temperature dropped below $0{ }^{\circ} \mathrm{C}$. The air was very clean, containing aged aerosol with low $N_{\text {tot }}$ and $N_{\text {acc }}$ (Table 6). Also, there were no nucleation mode particles, which was already shown to be typical for this wind sector (Fig. 2). A low $N_{\text {acc }}$ led to the lowest $N_{\mathrm{d}}$ of all the periods and a large $D_{\mathrm{d}}$.

The mass concentrations of inorganic components were somewhat higher during this period compared to the rainy period (Table 7). Also, their activated fraction was higher, meaning that a larger fraction of them was found in the accumulation mode particles. This suggests that the air mass 
Table 6. Average values and standard deviations of total particle number concentration $\left(N_{\text {tot }}\right)$, geometric mean particle diameter (GMD), accumulation mode particle number concentration $\left(N_{\mathrm{acc}}\right)$, diameter of $50 \%$ activation $\left(D_{50}\right)$, cloud droplet number concentration $\left(N_{\mathrm{d}}\right)$, droplet diameter $\left(D_{\mathrm{d}}\right)$ and liquid water content (LWC) for the different periods of the cloud event observed on 22-24 October 2011.

\begin{tabular}{llllllll}
\hline Period & $N_{\text {tot }}\left(\mathrm{cm}^{-3}\right)$ & GMD $(\mathrm{nm})$ & $N_{\mathrm{acc}}\left(\mathrm{cm}^{-3}\right)$ & $D_{50}(\mathrm{~nm})$ & $N_{\mathrm{d}}\left(\mathrm{cm}^{-3}\right)$ & $D_{\mathrm{d}}(\mu \mathrm{m})$ & $\mathrm{LWC}\left(\mathrm{g} \mathrm{m}^{-3}\right)$ \\
\hline rainy & $2200 \pm 576$ & $35 \pm 3$ & $149 \pm 37$ & $119 \pm 9$ & $219 \pm 69$ & $9.2 \pm 1.1$ & $0.11 \pm 0.04$ \\
clean & $451 \pm 195$ & $49 \pm 8$ & $62 \pm 18$ & $112 \pm 20$ & $138 \pm 32$ & $12.2 \pm 1.9$ & $0.17 \pm 0.08$ \\
paper mill & $357 \pm 74$ & $82 \pm 11$ & $139 \pm 44$ & $202 \pm 106$ & $240 \pm 53$ & $10.9 \pm 0.8$ & $0.22 \pm 0.04$ \\
clean 2 & $214 \pm 22$ & $77 \pm 5$ & $83 \pm 9$ & $146 \pm 28$ & $152 \pm 30$ & $11.8 \pm 0.6$ & $0.16 \pm 0.04$ \\
heating plant* & $1130 \pm 499$ & $35 \pm 9$ & $169 \pm 50$ & $273 \pm 89$ & - & - & - \\
southern 1* & $987 \pm 199$ & $29 \pm 7$ & $114 \pm 19$ & $118 \pm 17$ & - & - & - \\
southern 2 & $801 \pm 388$ & $40 \pm 10$ & $123 \pm 26$ & $118 \pm 30$ & $234 \pm 49$ & $10.0 \pm 1.0$ & $0.15 \pm 0.04$ \\
southern 3 & $754 \pm 135$ & $59 \pm 7$ & $169 \pm 41$ & $163 \pm 20$ & $197 \pm 50$ & $12.4 \pm 1.7$ & $0.30 \pm 0.09$ \\
\hline
\end{tabular}

* Cloud droplet probe frozen during these periods, data missing or otherwise unreliable.

Table 7. Average mass concentrations and standard deviations from the total line, activated concentration (difference in the mass concentration between total and interstitial lines) and activated fraction of chemical constituents for the different periods of the cloud event observed on 22-24 October 2011.

\begin{tabular}{|c|c|c|c|c|c|c|c|c|c|c|c|c|c|}
\hline \multirow[t]{2}{*}{ Period } & \multicolumn{3}{|c|}{ Organics } & \multicolumn{3}{|c|}{ Sulfate $\left(\mu \mathrm{g} \mathrm{m}^{-3}\right)$} & \multicolumn{3}{|c|}{ Nitrate $\left(\mu \mathrm{g} \mathrm{m}^{-3}\right)$} & \multicolumn{3}{|c|}{ Ammonium $\left(\mu \mathrm{g} \mathrm{m}^{-3}\right)$} & \multirow{2}{*}{$\begin{array}{l}\text { Inorg./ } \\
\text { total }(\%)\end{array}$} \\
\hline & $\operatorname{tot}\left(\mu \mathrm{g} \mathrm{m}^{-3}\right)$ & $\operatorname{act}\left(\mu \mathrm{g} \mathrm{m}^{-3}\right)$ & act frac $(\%)$ & $\operatorname{tot}\left(\mu \mathrm{g} \mathrm{m}^{-3}\right)$ & $\operatorname{act}\left(\mu \mathrm{g} \mathrm{m}^{-3}\right)$ & act frac $(\%)$ & $\operatorname{tot}\left(\mu \mathrm{g} \mathrm{m}^{-3}\right)$ & $\operatorname{act}\left(\mu \mathrm{g} \mathrm{m}^{-3}\right)$ & act frac $(\%)$ & $\operatorname{tot}\left(\mu \mathrm{g} \mathrm{m}^{-3}\right)$ & $\operatorname{act}\left(\mu \mathrm{g} \mathrm{m}^{-3}\right)$ & act frac $(\%)$ & \\
\hline rainy & $0.72 \pm 0.22$ & $0.45 \pm 0.26$ & $62 \pm 22$ & $0.16 \pm 0.06$ & $0.13 \pm 0.07$ & $78 \pm 14$ & $0.15 \pm 0.05$ & $0.12 \pm 0.05$ & $79 \pm 11$ & $0.05 \pm 0.03$ & $0.05 \pm 0.03$ & $94 \pm 9$ & $34 \pm 7$ \\
\hline clean & $0.42 \pm 0.28$ & $0.29 \pm 0.34$ & $71 \pm 52$ & $0.20 \pm 0.15$ & $0.18 \pm 0.15$ & $91 \pm 15$ & $0.23 \pm 0.05$ & $0.21 \pm 0.05$ & $91 \pm 7$ & $0.10 \pm 0.05$ & $0.10 \pm 0.05$ & $98 \pm 6$ & $59 \pm 14$ \\
\hline paper mill & $0.69 \pm 0.16$ & $0.58 \pm 0.2$ & $84 \pm 17$ & $2.46 \pm 0.86$ & $2.2 \pm 0.90$ & $90 \pm 12$ & $0.42 \pm 0.01$ & $0.35 \pm 0.07$ & $85 \pm 16$ & $0.99 \pm 0.31$ & $0.90 \pm 0.33$ & $91 \pm 12$ & $85 \pm 2$ \\
\hline clean 2 & $0.61 \pm 0.12$ & $0.50 \pm 0.22$ & $82 \pm 30$ & $0.57 \pm 0.08$ & $0.49 \pm 0.09$ & $86 \pm 08$ & $0.27 \pm 0.04$ & $0.24 \pm 0.04$ & $88 \pm 5$ & $0.24 \pm 0.04$ & $0.23 \pm 0.04$ & $95 \pm 4$ & $64 \pm 4$ \\
\hline heating plant & $0.69 \pm 0.30$ & $0.56 \pm 0.34$ & $80 \pm 26$ & $4.43 \pm 1.62$ & $3.4 \pm 1.81$ & $77 \pm 20$ & $0.08 \pm 0.08$ & $0.06 \pm 0.08$ & $78 \pm 29$ & $0.52 \pm 0.34$ & $0.46 \pm 0.36$ & $87 \pm 23$ & $87 \pm 7$ \\
\hline southern 1 & $0.72 \pm 0.17$ & $0.57 \pm 0.29$ & $80 \pm 34$ & $0.47 \pm 0.19$ & $0.44 \pm 0.19$ & $95 \pm 7$ & $0.14 \pm 0.03$ & $0.13 \pm 0.03$ & $89 \pm 5$ & $0.13 \pm 0.05$ & $0.13 \pm 0.05$ & $99 \pm 1$ & $51 \pm 9$ \\
\hline southern 2 & $0.81 \pm 0.23$ & $0.66 \pm 0.30$ & $82 \pm 25$ & $0.66 \pm 0.28$ & $0.62 \pm 0.29$ & $93 \pm 8$ & $0.15 \pm 0.07$ & $0.13 \pm 0.07$ & $89 \pm 7$ & $0.16 \pm 0.06$ & $0.16 \pm 0.06$ & $99 \pm 2$ & $54 \pm 8$ \\
\hline southern 3 & $1.28 \pm 0.36$ & $0.83 \pm 0.43$ & $65 \pm 21$ & $0.46 \pm 0.25$ & $0.37 \pm 0.26$ & $81 \pm 19$ & $0.17 \pm 0.08$ & $0.13 \pm 0.08$ & $79 \pm 17$ & $0.12 \pm 0.10$ & $0.11 \pm 0.11$ & $94 \pm 21$ & $38 \pm 6$ \\
\hline
\end{tabular}

was aged and had gone through some cloud processing, producing internally mixed aerosol before arriving to Puijo. This is also supported by high values for the hygroscopic growth factors (Table 8 ). The hygroscopicity distribution was dominated by the more hygroscopic mode, especially for the 100 and $150 \mathrm{~nm}$ particles, as indicated by the high $R_{\mathrm{GF}}$ values. The $R_{\mathrm{GF}}$ of 100 and $150 \mathrm{~nm}$ particles was also strongly dependent on the concentration of sulfate. In the beginning of the period, sulfate was almost absent, but throughout the period, its mass fraction increased to $45 \%$. $R_{\mathrm{GF}}$ was around 2 and 6 in the beginning of the period but towards the end increased to 7 and 40 for 100 and $150 \mathrm{~nm}$ particles, respectively (Figs. 5c, 7). The average $\mathrm{GF}_{100}$ was 1.42 , comparable with the Jungfraujoch free-tropospheric aerosol, which is also aged and internally mixed (Sjogren et al., 2008; Kammermann et al., 2010).

\subsubsection{Paper mill period}

This short 30 min period was characterized by a heavy pollution plume from the nearby paper mill. There was no rain and the temperature was below $0{ }^{\circ} \mathrm{C}$. The particle population properties differed greatly from those observed during the other periods. $N_{\text {tot }}$ was very low but $N_{\text {acc }}$ was elevated (Table 6). Due to the pronounced accumulation mode, a very high $D_{50}, 202 \mathrm{~nm}$, was observed, compared to the normal
$D_{50}$ at Puijo of around $120 \mathrm{~nm}$, as was the case during the first two periods.

A time series of the cloud droplet data for the whole cloud event is shown in Fig. 5b. During the paper mill plume $N_{\mathrm{d}}$ increased momentarily, coinciding with a quick decrease in the average droplet size. This sharp change in the droplet population properties was mainly caused by the high $N_{\text {acc }}$, but the possibility that the different chemical composition of particles also played a role cannot be excluded. The inorganic components all experienced a drastic increase, with sulfate dominating the composition (Table 7). Growth factor distributions also showed elevated hygroscopicity for the high- $\mathrm{GF}_{\mathrm{H}}$ mode, especially for the larger particles (Fig. 6f). However, the presence of a low- $\mathrm{GF}_{\mathrm{H}}$ mode, probably containing soot particles, lowered the average hygroscopicities during the plume (Table 8). For example, the average $\mathrm{GF}_{100}$ was 1.37 , whereas for the high-hygroscopicity mode it was around 1.6. It has to be noted, though, that only one or two hygroscopicity measurements for each particle size were available for this very short period, so the $\mathrm{GF}_{\mathrm{H}}$ values likely have large uncertainties and have to be treated with caution.

\subsubsection{Clean 2 period}

In the beginning of this period, the wind direction shifted back to the north, fluctuating between the clean sector and sector 1 , with no rain and a temperature of just below $0{ }^{\circ} \mathrm{C}$. 
Table 8. Average values and standard deviations of particle hygroscopic growth factors $\mathrm{GF}_{\mathrm{H}}$ and the ratios between more and less hygroscopic particle number concentrations, $R_{\mathrm{GF}}=N_{\mathrm{GF}>1.25} / N_{\mathrm{GF} \leq 1.25}$ for the different periods of the cloud event observed on 22-24 October 2011 .

\begin{tabular}{lll|ll|ll}
\hline & \multicolumn{2}{c|}{$80 \mathrm{~nm}$} & \multicolumn{2}{c|}{$100 \mathrm{~nm}$} & \multicolumn{2}{c}{$150 \mathrm{~nm}$} \\
\cline { 2 - 7 } Period & $\mathrm{GF}_{\mathrm{H}}$ & $R_{\mathrm{GF}}$ & $\mathrm{GF}_{\mathrm{H}}$ & $R_{\mathrm{GF}}$ & $\mathrm{GF}_{\mathrm{H}}$ & $R_{\mathrm{GF}}$ \\
\hline rainy & $1.16 \pm 0.04$ & $0.42 \pm 0.12$ & $1.25 \pm 0.04$ & $1.43 \pm 0.45$ & $1.33 \pm 0.02$ & $2.69 \pm 0.63$ \\
clean & $1.24 \pm 0.05$ & $0.79 \pm 0.39$ & $1.42 \pm 0.08$ & $4.90 \pm 2.47$ & $1.55 \pm 0.08$ & $26.0 \pm 16.4$ \\
paper mill & $1.17 \pm 0.02$ & $0.44 \pm 0.07$ & $1.37 \pm 0.01$ & $2.06 \pm 0.34$ & $1.56 \pm 0.06$ & $23.9 \pm 10.9$ \\
clean 2 & $1.28 \pm 0.04$ & $1.29 \pm 0.44$ & $1.45 \pm 0.03$ & $9.13 \pm 4.29$ & $1.53 \pm 0.02$ & $5.15 \pm 1.56$ \\
heating plant & $1.24 \pm 0.11$ & $1.09 \pm 1.02$ & $1.36 \pm 0.09$ & $3.74 \pm 3.79$ & $1.48 \pm 0.03$ & $8.75 \pm 6.83$ \\
southern 1 & $1.22 \pm 0.05$ & $0.92 \pm 0.41$ & $1.32 \pm 0.12$ & $3.73 \pm 3.84$ & $1.39 \pm 0.03$ & $12.8 \pm 8.93$ \\
southern 2 & $1.20 \pm 0.06$ & $0.62 \pm 0.31$ & $1.34 \pm 0.07$ & $2.50 \pm 1.29$ & $1.43 \pm 0.04$ & $3.03 \pm 1.18$ \\
southern 3 & $1.17 \pm 0.03$ & $0.36 \pm 0.15$ & $1.21 \pm 0.03$ & $0.88 \pm 0.32$ & $1.34 \pm 0.05$ & $7.64 \pm 2.78$ \\
rainy & $1.16 \pm 0.04$ & $0.42 \pm 0.12$ & $1.25 \pm 0.04$ & $1.43 \pm 0.45$ & $1.33 \pm 0.02$ & $2.69 \pm 0.63$ \\
\hline
\end{tabular}

This period shared many similarities with the clean period. $N_{\text {tot }}$ was even lower, nucleation mode particles were absent and a pronounced accumulation mode was observed (Fig. 6a, Table 6), indicating that strong cloud processing had taken place before the air mass arrived to Puijo.

The main difference compared with the clean period was an elevated inorganic mass concentration, largely due to 2-3 times higher sulfate and ammonium concentrations (Table 7). This indicates that the air mass had probably encountered some anthropogenic influence on its way to Puijo, but not from nearby sources. This had a clear influence on particle hygroscopicity, as seen from the high $\mathrm{GF}_{\mathrm{H}}$ and $R_{\mathrm{GF}}$ values (Table 8 ) but not on cloud droplet activation. $N_{\mathrm{d}}$ was $10 \%$ higher than during the clean period (Table 6), which is of similar magnitude to the difference in $N_{\text {acc }}$ between the periods.

\subsubsection{Heating plant period}

The period started with a rapid shift in the wind direction from north to south and the polluted sector. The temperature was still slightly below $0{ }^{\circ} \mathrm{C}$. At the same time, a heavy pollutant plume from the heating plant reached the tower. The particle population consisted of pronounced nucleation and accumulation modes (Fig. $6 \mathrm{a}$ ). $N_{\text {acc }}$ was the highest of all the periods, and the particles consisted mainly of sulfate (Fig. 5c). Also, as the aerosol was highly acidic, the nitrate concentration was very low. The plume also contained an exceptionally high amount of $\mathrm{SO}_{2}$ (Fig. 5d), so it is likely that the majority of the sulfate observed in the activated particles was formed from $\mathrm{SO}_{2}$ as a result of cloud processing. However, sulfate also dominated the composition of cloud interstitial particles. Since the smaller, unactivated particles are also liquid at high $\mathrm{RH}$, it is possible that cloud processing from $\mathrm{SO}_{2}$ to sulfate also took place in the interstitial aerosol. Another explanation is that part of the sulfate particles had already formed at the heating plant.

The conclusions about particle activation parameters for this period have to be made carefully as the time resolution of the distribution scan is not good enough to capture the observed rapid changes in the aerosol properties. For example, $D_{50}$ was very high, $273 \mathrm{~nm}$, (Table 6) but this does not necessarily represent the actual size of the activating particles. The activated fraction of particles as a function of size (Fig. 6c) showed a bimodal behavior. Particles with a diameter of around $100 \mathrm{~nm}$ had already started to activate, similar to some other periods, but reached only an activation fraction of $40 \%$ at $150 \mathrm{~nm}$. After this there is a dip in the curve as the heating plant particles started to affect the activation curve and produced a seemingly high $D_{50}$.

The $\mathrm{GF}_{\mathrm{H}}$ distributions showed a clear bimodal behavior, with the high- $\mathrm{GF}_{\mathrm{H}}$ mode slightly elevated by the heating plant particles. The low mode was also pronounced and, for 100 and $150 \mathrm{~nm}$ particles, similar to the observations during the rainy period, indicating emissions from traffic and residential areas. For $80 \mathrm{~nm}$ particles there was a clear increase in the low $\mathrm{GF}_{\mathrm{H}}$ mode, indicating that the plume contained significant amounts of small particles with low hygroscopicity, likely soot. Since both hygroscopicity modes were affected by the plume, $R_{\mathrm{GF}}$ remained moderate. Unfortunately the CDP froze shortly after the beginning of the period, making analysis of the cloud properties impossible.

\subsubsection{Southern 1 period}

During this period, the conditions returned to normal as the heating plant plume passed the tower. The temperature rose above $0{ }^{\circ} \mathrm{C}$ during the period and the wind direction was still from the south and the polluted sector. Similar nucleation and Aitken modes were present as during the heating plant plume (Fig. 6a). For the chemical components the concentrations were quite normal (Table 7). The $\mathrm{GF}_{\mathrm{H}}$ distributions were similar to those observed during the rainy period with bimodal shapes and moderate average $\mathrm{GF}_{\mathrm{H}}$ and $R_{\mathrm{GF}}$ (Table 8). As the heating plant had no effect on data during the rainy period, it is likely that this was the case also here. Thus, southern 1 can be considered to represent normal "semipolluted" conditions for this sector when the effects of 


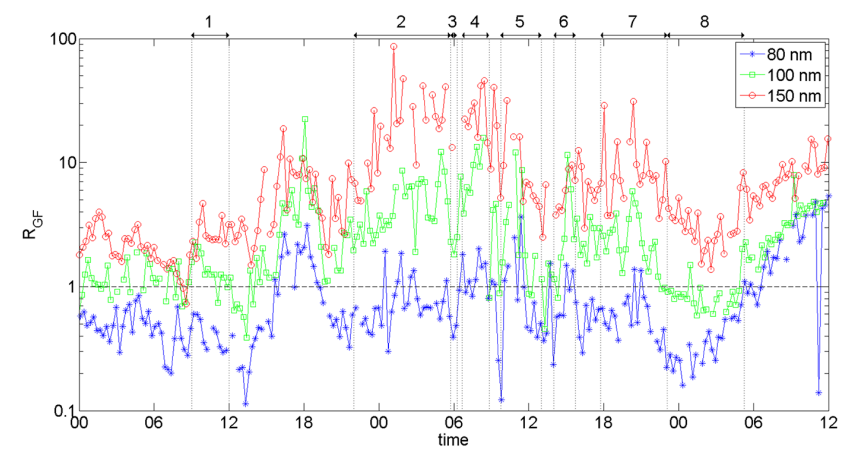

Figure 7. Time series of the ratio between the number concentrations of more and less hygroscopic particles, $R_{\mathrm{GF}}=$ $N_{\mathrm{GF}>1.25} / N_{\mathrm{GF} \leq 1.25}$, observed during the cloud event on $22-24$ October 2011. Different periods described in the text are marked with dashed lines and also with numbered arrows (1, rainy; 2 , clean; 3 , paper mill; 4 , clean $2 ; 5$, heating plant; 6 , southern $1 ; 7$, southern 2 ; and 8 , southern 3 ).

the heating plant and weather are minor. The CDP was still frozen part of the time, so no reliable droplet data are available.

\subsubsection{Southern 2 period}

After a short clear period, the tower was again covered in cloud, with southerly wind and a temperature of above $0{ }^{\circ} \mathrm{C}$. The aerosol during this period was moderately affected by the heating plant, indicated by the elevated sulfate and $\mathrm{SO}_{2}$ concentrations (Fig. 5). Also the concentration of organics was higher than during the earlier periods, which might have already been related to the transportation of organic aerosol, which was more pronounced during the next period, southern 3. The presence of two different kinds of aerosols had some effect on the activation of particles. The activated fraction curve was less steep than for most of the other periods and the size distribution of activated particles was broader (Fig. 5b, c). Also bimodal $\mathrm{GF}_{\mathrm{H}}$ distributions and low $R_{\mathrm{GF}}$ indicated the presence of externally mixed aerosol. $R_{\mathrm{GF}}$ also (Fig. 7) correlated with sulfate and $\mathrm{SO}_{2}$ concentrations, with higher values in the middle of the period.

The cloud droplet size distribution was unimodal, similar to the rainy period. This suggests that the unimodality is an occasional feature for southerly clouds and not related to removal of droplets by rain as suggested for the rainy period. However, this does not exclude the possibility that rain removal of droplets was taking place during the rainy period. $N_{\mathrm{d}}$ during this period was higher despite a lower $N_{\text {acc }}$ compared to the rainy period (Table 6).

\subsubsection{Southern 3 period}

During southern 3 period, wind was still blowing from the south. The period started with a drop in the mass concentration of sulfate and in the concentration of $\mathrm{SO}_{2}$ (Fig. 5). At the same time, the organic mass concentration increased to the highest value during the whole event (Table 7). The rise in the amount of organics was explained by an increase in $N_{\text {acc }}$, although $N_{\text {tot }}$ remained lower than during other southern periods. As the chemical composition and $N_{\text {tot }}$ showed little variance during the period (Fig. 5), this would suggest that the effect of local sources was minor. It is likely that these large organic particles were transported to Puijo from somewhere else.

These organic particles were also characterized by low hygroscopicity (Table 8 ). For $80 \mathrm{~nm}$ particles the hygroscopicity distribution was unimodal, with one broad peak centered at $\mathrm{GF}_{\mathrm{H}}=1.1$. Also, for the $150 \mathrm{~nm}$ particles the low and high hygroscopicity peaks were broader than for the other periods (Fig. 6e, f). It is possible that some of the larger particles remained unactivated because of this, as suggested by the unusually high $D_{50}$ (Table 6). The availability of water was not a limiting factor. Although $N_{\mathrm{d}}$ was quite normal, the droplets were the largest and LWC the highest of all the periods.

\subsection{Ratio of inorganics to total mass}

Also shown in Table 7 is the IO from the AMS measurements for each of the periods. IO was the lowest for the rainy and southern 3 periods, 34 and $38 \%$, respectively, and higher for the clean, clean 2 , southern 1 and southern 2 periods, $59,64,51$ and $54 \%$, respectively. The highest IOs were observed during the paper mill and heating plant plumes, 85 and $87 \%$, respectively. The differences between the periods were considerably larger than those between the different air masses analyzed in Dusek et al. (2006) (18-42\%) and Kivekäs et al. (2009) (23-44\%). This further supports our findings that the local pollutant sources also have the potential to affect aerosol-cloud interactions through the particle chemical composition.

\section{Summary and conclusions}

Aerosol-cloud interactions were investigated during two intensive measurement campaigns at Puijo measurement site during autumns 2010-2011. The object was to determine the possible effects of local pollutant sources and particle chemical composition on aerosol-cloud interactions. The first approach was to compare data from two different wind direction sectors for the whole data set. One sector was considered to be clean, with no nearby aerosol sources. The other sector was affected by local pollutant sources, including residential areas, traffic and a heating plant.

In clear conditions, the total particle number concentration and the accumulation mode concentration were 2930 and $580 \mathrm{~cm}^{-3}$ for the polluted and 2000 and $146 \mathrm{~cm}^{-3}$ for the clean sector, respectively. In cloudy conditions cloud processing took place, leading to lower total particle concentrations of 1680 and $972 \mathrm{~cm}^{-3}$ for the polluted and clean 
air, respectively. However, unlike for the polluted sector $\left(438 \mathrm{~cm}^{-3}\right)$, the accumulation mode concentration increased for the clean sector $\left(349 \mathrm{~cm}^{-3}\right)$, indicating stronger cloud processing. The in-cloud mass concentrations of particle chemical components in polluted air were $1.79,1.08,0.19$ and $0.27 \mu \mathrm{g} \mathrm{m}^{-3}$ for organics, sulfate, nitrate and ammonium, respectively, and the corresponding numbers for the clean air were $1.61,0.69,0.24$ and $0.27 \mu \mathrm{g} \mathrm{m}^{-3}$. The main difference was the higher amount of sulfates for the polluted sector. Despite some differences in the particle properties, the droplet activation behavior was surprisingly similar for the two sectors. The average diameters for which $50 \%$ of the particles activated were 170 and $164 \mathrm{~nm}$ for the polluted and clean air, respectively. For the polluted sector the average droplet concentration was higher ( 293 vs. $266 \mathrm{~cm}^{-3}$ ) and the average diameter smaller ( 8.3 vs. $8.9 \mu \mathrm{m})$ than for the clean sector.

The second approach was a case study of a cloud event with variable conditions. The wind was blowing from both the clean and polluted sectors, and plumes from the local heating plant and paper mill were observed. The total (from 754 to $2200 \mathrm{~cm}^{-3}$ ) and accumulation mode (from 114 to $169 \mathrm{~cm}^{-3}$ ) particle concentrations were clearly elevated for the polluted sector compared to the clean sector (from 214 to $451 \mathrm{~cm}^{-3}$ and from 62 to $83 \mathrm{~cm}^{-3}$, respectively). This also created large differences in the droplet properties, with higher concentrations (from 197 to $234 \mathrm{~cm}^{-3}$ vs. from 138 to $152 \mathrm{~cm}^{-3}$ ) and generally smaller droplet mean diameters (from 9.2 to 12.4 vs. from 11.8 to $12.2 \mu \mathrm{m}$ ) for the polluted sector compared to the clean sector, respectively.

Aged, cloud-processed air masses from the clean sector typically resulted in an internally mixed, more hygroscopic aerosol with an inorganic fraction of around $60 \%$ and hygroscopic growth factor at $90 \%$ for $100 \mathrm{~nm}$ particles $\left(\mathrm{GF}_{\mathrm{H}}\right)$ from 1.42 to 1.45 . With southerly winds, the particle hygroscopicity distributions were clearly bimodal, with one mode centered around $\mathrm{GF}_{\mathrm{H}}=1.0$ and the other mode between 1.4 and 1.5 , suggesting externally mixed aerosols. Likely sources for the less hygroscopic particles include local domestic wood combustion and traffic. The concentration of organics was higher, as indicated by the lower inorganic fraction between 30 and $50 \%$.

The paper mill plume was short in duration but a high accumulation mode particle concentration $\left(139 \mathrm{~cm}^{-3}\right)$ was observed, leading to a momentary increase in droplet concentration $\left(240 \mathrm{~cm}^{-3}\right)$ and a decrease in droplet size $(10.9 \mu \mathrm{m})$. The heating plant plume caused an even bigger increase in the accumulation mode concentration $\left(169 \mathrm{~cm}^{-3}\right)$. In both the paper mill and the heating plant plumes, elevated amounts of sulfate (2.46 and $\left.4.43 \mu \mathrm{g} \mathrm{m}^{-3}\right)$ and ammonium (0.99 and $0.52 \mu \mathrm{g} \mathrm{m}^{-3}$ ) were observed, respectively, leading to inorganic fractions of over $80 \%$. Unlike the paper mill plume, the heating plant plume also contained a large amount of $\mathrm{SO}_{2}$. Thus, the sulfate from the heating plant was formed from $\mathrm{SO}_{2}$ as a result of cloud processing. For the paper mill plume, the sulfate particles were either generated at the mill or $\mathrm{SO}_{2}$ was present to a lesser extent and was completely transformed into particulate sulfate before arriving at Puijo. Another difference was the nitrate concentration, which was elevated in the paper mill plume $\left(0.42 \mu \mathrm{g} \mathrm{m}^{-3}\right)$ but very low in the heating plant plume $\left(0.08 \mu \mathrm{g} \mathrm{m}^{-3}\right)$ due to highly acidic aerosol. In both plumes, elevated amounts of more hygroscopic particles $\left(\mathrm{GF}_{\mathrm{H}}\right.$ between 1.5 and 1.6) were observed in addition to smaller, hydrophobic soot particles $\left(\mathrm{GF}_{\mathrm{H}}=1.0\right)$.

As a conclusion, the case study presented here supported and complemented the results from the sector comparison, and the main results from these two methods can be summarized as follows: (1) the particle concentration in aged, cloudprocessed, internally mixed and more hygroscopic air masses is low but a pronounced accumulation mode is present, leading to fewer cloud droplets with larger size. (2) Air masses affected by local sources contain more nucleation and Aitken mode particles with lower hygroscopicity. The aerosol is externally mixed with a higher inorganic content. The cloud droplets are smaller but more numerous. (3) Local point sources have the potential to affect aerosol-cloud interactions both through an increased particle concentration and through their effect on chemistry.

Acknowledgements. This work was partly supported by the Academy of Finland (Centre of Excellence, no. 1118615 and decision number 267514), and the strategic funding of the University of Eastern Finland. L. Hao acknowledges the financial support of UEF Postdoc Research Foundation (no. 930275).

Edited by: V.-M. Kerminen

\section{References}

Ahmad, I., Mielonen, T., Grosvenor, D. P., Portin, H., Arola, A., Mikkonen, S., Kühn, T., Leskinen, A., Joutsensaari J., Komppula, M., Lehtinen, K. E. J., Laaksonen, A., and Romakkaniemi, S.: Long-term measurements of cloud droplet concentrations and aerosol-cloud interactions in continental boundary layer clouds, Tellus B, 65, 20138, doi:10.3402/tellusb.v65i0.20138, 2013.

Albrecht, B. A.: Aerosols, cloud microphysics, and fractional cloudiness, Science, 245, 1227-1230, 1989.

Anttila, T., Vaattovaara, P., Komppula, M., Hyvärinen, A.-P., Lihavainen, H., Kerminen, V.-M., and Laaksonen, A.: Sizedependent activation of aerosols into cloud droplets at a subarctic background site during the second Pallas Cloud Experiment (2nd PaCE): method development and data evaluation, Atmos. Chem. Phys., 9, 4841-4854, doi:10.5194/acp-9-4841-2009, 2009.

Asmi, E., Freney, E., Hervo, M., Picard, D., Rose, C., Colomb, A., and Sellegri, K.: Aerosol cloud activation in summer and winter at puy-de-Dôme high altitude site in France, Atmos. Chem. Phys., 12, 11589-11607, doi:10.5194/acp-12-11589-2012, 2012.

Brenguier, J.-L. and Bourrianne, T.: Improvements of Droplet Size Distribution Measurements with the Fast-FSSP (Forward Scattering Spectrometer Probe), J. Atmos. Ocean. Tech., 15, 10771090, 1998. 
Brenguier, J.-L., Pawlowska, H., and Schuller, L.: Cloud microphysical and radiative properties for parameterization and satellite monitoring of the indirect effect of aerosols on climate, J. Geophys. Res., 108, 8632, doi:10.1029/2002JD002682, 2003.

Coakley, J. A. and Walsh, C. D.: Limits to the aerosol indirect effect derived from obsevations of ship tracks, J. Atmos. Sci., 59, 668680, 2002.

DeCarlo, P. F., Kimmel, J. R., Trimborn, A., Northway, M. J., Jayne, J. T., Aiken, A. C., Gonin, M., Fuhrer, K., Horvath, T., Docherty, K. S., Worsnop, D. R., and Jimenez, J. L.: Field-deployable, high-resolution, time-of-flight aerosol mass spectrometer, Anal. Chem., 78, 8281-8289, 2006.

Drewnick, F., Schneider, J., Hings, S. S., Hock, N., Noone, K., Targino, A., Weimer, S., and Borrmann, S.: Measurement of ambient, interstitial, and residual aerosol particles on a mountaintop site in central Sweden using an aerosol mass spectrometer and a CVI, J. Atmos. Chem., 56, 1-20, 2007.

Dusek, U., Frank, G. P., Hildebrandt, L., Curtius, J., Schneider, J., Walter, S., Chand, D., Drewnick, F., Hings, S., Jung, D., Borrmann, S., and Andreae, M. O.: Size matters more than chemistry for cloud-nucleating ability of aerosol particles, Science, 312, 1375-1378, 2006.

Fors, E. O., Swietlicki, E., Svenningsson, B., Kristensson, A., Frank, G. P., and Sporre, M.: Hygroscopic properties of the ambient aerosol in southern Sweden - a two year study, Atmos. Chem. Phys., 11, 8343-8361, doi:10.5194/acp-11-8343-2011, 2011.

Frick, G. M. and Hoppel, W. A.: Airship Measurements of Aerosol Size Distributions, Cloud Droplet Spectra, and Trace Gas Concentrations in the Marine Boundary Layer, B. Am. Meteorol. Soc., 74, 2195-2202, 1993.

Han, Q., Rossow, W. B., Zeng, J., and Welch, R.: Three different behaviors of liquid water path of water clouds in aerosol-cloud interactions, J. Atmos. Sci., 59, 726-735, 2002.

Hao, L. Q., Romakkaniemi, S., Kortelainen, A., Jaatinen, A., Portin, H., Miettinen, P., Komppula, M., Leskinen, A., Virtanen, A., Smith, J. N., Sueper, D., Worsnop, D. R., Lehtinen, K. E. J., and Laaksonen, A.: Aerosol Chemical Composition in Cloud Events by High Resolution Time-of-Flight Aerosol Mass Spectrometry, Environ. Sci. Technol., 47, 2645-2653, 2013.

Henning, S., Weingartner, E., Schmidt, S., Wendisch, M., Gäggeler, H. W., and Baltensperger, U.: Size-dependent aerosol activation at the high-alpine site Jungfraujoch (3580 m a.s.1), Tellus B, 54, 82-95, 2002.

Herich, H., Kammermann, L., Friedman, B., Gross, D. S., Weingartner, E., Lohmann, U., Spichtinger, P., Gysel, M., Baltensperger, U., and Cziczo, D. J.: Subarctic atmospheric aerosol composition: 2. Hygroscopic growth properties, J. Geophys. Res., 114, D13204, doi:10.1029/2008JD011574, 2009.

Hinds, W. C.: Aerosol Technology. Properties, Behavior and Measurement of Airborne Particles. New York, USA: Wiley Interscience, 1999.

Hoppel, W. A., Frick, G. M., and Larson, R. E.: Effect of nonprecipitating clouds on the aerosol size distribution in the marine boundary layer, Geophys. Res. Lett., 13, 125-128, 1986.

Hudson, J. G.: Variability of the relationship between particle size and cloud-nucleating ability, Geophys. Res. Lett., 34, L08801, doi:10.1029/2006GL028850, 2007.
IPCC: Climate change 2013: The physical science basis. Intergovernmental panel on Climate Change, Cambridge University Press, New York, 2013.

Jokinen, V. and Mäkelä, J. M.: Closed-loop arrangement with critical orifice for DMA sheath/excess flow system, J. Aerosol Sci., 28, 643-648, 1997.

Joutsensaari, J., Vaattovaara, P., Vesterinen, M., Hämeri, K., and Laaksonen, A.: A novel tandem differential mobility analyzer with organic vapor treatment of aerosol particles, Atmos. Chem. Phys., 1, 51-60, doi:10.5194/acp-1-51-2001, 2001.

Kammermann, L., Gysel, M., Weingartner, E., and Baltensperger, U.: 13-month climatology of the aerosol hygroscopicity at the free tropospheric site Jungfraujoch (3580 m a.s.1.), Atmos. Chem. Phys., 10, 10717-10732, doi:10.5194/acp-10-107172010, 2010.

Kivekäs, N., Kerminen, V.-M., Raatikainen, T., Vaattovaara, P., Laaksonen, A., and Lihavainen, H.: Physical and chemical characteristics of aerosol particles and cloud-droplet activation during the Second Pallas Cloud Experiment (Second PaCE), Boreal Environ. Res., 14, 515-526, 2009.

Komppula, M., Lihavainen, H., Kerminen, V.-M., Kulmala, M., and Viisanen, Y.: Measurements of cloud droplet activation of aerosol particles at a clean subarctic background site, J. Geophys. Res., 110, D06204, doi:10.1029/2004JD005200, 2005.

Leskinen, A., Portin, H., Komppula, M., Miettinen, P., Arola, A., Lihavainen, H., Hatakka, J., Laaksonen, A., and Lehtinen, K. E. J.: Overview of the research activities and results at Puijo semiurban measurement station, Boreal Environ. Res., 14, 576-590, 2009.

Leskinen, A., Arola, A., Komppula, M., Portin, H., Tiitta, P., Miettinen, P., Romakkaniemi, S., Laaksonen, A., and Lehtinen, K. E. J.: Seasonal cycle and source analyses of aerosol optical properties in a semi-urban environment at Puijo station in Eastern Finland, Atmos. Chem. Phys., 12, 5647-5659, doi:10.5194/acp-12-56472012, 2012.

Lohmann, U. and Feichter, J.: Global indirect aerosol effects: a review, Atmos. Chem. Phys., 5, 715-737, doi:10.5194/acp-5-7152005, 2005.

Menon, S., Del Genio, A. D., Koch, D., and Tseloudis, G.: GCM simulations of the aerosol indirect effect: sensitivity to cloud parameterization and aerosol burden, J. Atmos. Sci., 59, 692-713, 2002.

Mochida, M., Nishita-Hara, C., Furutani, H., Miyazaki, Y., Jung, J., Kawamura, K., and Uematsu, M.: Hygroscopicity and cloud condensation nucleus activity of marine aerosol particles over the western North Pacific, J. Geophys. Res., 116, D06204, doi:10.1029/2010JD014759, 2011.

Portin, H., Komppula, M., Leskinen, A., Romakkaniemi, S., Laaksonen, A., and Lehtinen, K. E. J.: Observations of aerosol-cloud interactions at Puijo semi-urban measurement station, Boreal Environ. Res., 14, 641-653, 2009.

Rotstayn, L. D. and Liu, Y.: A smaller global estimate of the second indirectaerosol effect, Geophys. Res. Lett., 32, L05708, doi:10.1029/2004GL021922, 2005.

Sekiguchi, M., Nakajima, T., Suzuki, K., Kawamoto, K., Higurashi, A., Rosenfeld, D., Sano, I., and Mukai, S.: A study of the direct and indirect effects of aerosols and cloud parameters, J. Geophys. Res., 108, 4699, doi:10.1029/2002JD003359, 2003. 
Sjogren, S., Gysel, M., Weingartner, E., Alfarra, M. R., Duplissy, J., Cozic, J., Crosier, J., Coe, H., and Baltensperger, U.: Hygroscopicity of the submicrometer aerosol at the high-alpine site Jungfraujoch, $3580 \mathrm{~m}$ a.s.l., Switzerland, Atmos. Chem. Phys., 8, 5715-5729, doi:10.5194/acp-8-5715-2008, 2008.

Twomey, S.: The influence of pollution on the shortwave albedo of clouds, J. Atmos. Sci., 34, 1149-1152, 1977.

Vong, R. J. and Covert, D. S.: Simultaneous observations of aerosol and cloud droplet size spectra in marine stratocumulus, J. Atmos. Sci., 55, 2180-2190, 1998.

Wang, J., Lee, Y.-N., Daum, P. H., Jayne, J., and Alexander, M. L.: Effects of aerosol organics on cloud condensation nucleus (CCN) concentration and first indirect aerosol effect, Atmos. Chem. Phys., 8, 6325-6339, doi:10.5194/acp-8-6325-2008, 2008.

Winklmayr, W., Reischl, G. P., Linder, A. O., and Berner, A.: A new electromobility spectrometer for the measurement of aerosol size distribution in the size range 1 to $1000 \mathrm{~nm}$, J. Aerosol Sci., 22, 289-296, 1991.
Wiedensohler, A., Birmili, W., Nowak, A., Sonntag, A., Weinhold, K., Merkel, M., Wehner, B., Tuch, T., Pfeifer, S., Fiebig, M., Fjäraa, A. M., Asmi, E., Sellegri, K., Depuy, R., Venzac, H., Villani, P., Laj, P., Aalto, P., Ogren, J. A., Swietlicki, E., Williams, P., Roldin, P., Quincey, P., Hüglin, C., Fierz-Schmidhauser, R., Gysel, M., Weingartner, E., Riccobono, F., Santos, S., Grüning, C., Faloon, K., Beddows, D., Harrison, R., Monahan, C., Jennings, S. G., O’Dowd, C. D., Marinoni, A., Horn, H.-G., Keck, L., Jiang, J., Scheckman, J., McMurry, P. H., Deng, Z., Zhao, C. S., Moerman, M., Henzing, B., de Leeuw, G., Löschau, G., and Bastian, S.: Mobility particle size spectrometers: harmonization of technical standards and data structure to facilitate high quality long-term observations of atmospheric particle number size distributions, Atmos. Meas. Tech., 5, 657-685, doi:10.5194/amt5-657-2012, 2012.

Wu, Z. J., Poulain, L., Henning, S., Dieckmann, K., Birmili, W., Merkel, M., van Pinxteren, D., Spindler, G., Müller, K., Stratmann, F., Herrmann, H., and Wiedensohler, A.: Relating particle hygroscopicity and $\mathrm{CCN}$ activity to chemical composition during the HCCT-2010 field campaign, Atmos. Chem. Phys., 13, 79837996, doi:10.5194/acp-13-7983-2013, 2013. 